\title{
Postoperative respiratory failure in esophageal surgery
}

Prieto Sánchez A, Polo Martínez S, Marín Posada PA, Ferrandis Comes R, Vicente Guillén R, Argente Navarro P. Department of Anaesthesia and Postoperative Intensive Care, Hospital Universitari i Politécnic La Fe, Valencia, Spain

\section{Background and goals of study}

Respiratory complications constitute the most frequent early complication in esophageal surgery (ES). We present a pilot study to analyse the incidence of respiratory failure (RF) in patients subjected to ES, both in the initial income and re-entry (main goal).

Secondary goals, in respect to RF:

- Personal and perioperative risk factors

- Involvement in critical care unit (CCU)

- Prognostic factor

\section{Material and methods}

- Retrospective unicenter study

Consecutive ES cases between September 1st, 2013 and September 1st, 2016.

- Collected variables:

- Preoperative: age, gender, previous pulmonary disease.

- Intraoperative: surgery type and length, abdominal and/or thoracic access, extubation at operating theatre, fluid and transfusion therapy.

- Postoperative: income stay length, RF development, mechanical ventilatory therapy (non-invasive-NIMV and invasive-IMV), hydric balance.

- Re-entry: re-entry reason, RF development, day of evolution, re-entry stay length in postoperative CCU, RI development, MV.

- Morbidity and Mortality: discharge cause (improvement or death), death cause, complications.

- Statistic study: descriptive analysis (mean and standard deviation), using no parametric test (Chi Squared) for their comparison (SPSS Stadistics $@ 2$ 2nd version), regarding $p$ value $<0,05$ as significative.

\section{Results and discussion}

$N=65$

$($ male $=56$, female $=9)$

$61 \pm 10$ years old

Previous respiratory disease

$\longrightarrow 9 \%$

tuberculosis;

$$
5 \%
$$

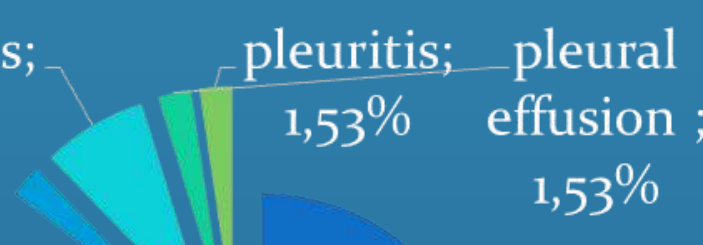

chronic

ronchitis ;

tobbaco use; $55 \%$

$\mathrm{NO}$ $32 \%$

\section{YES $68 \%$ \\ ¿ smoker $\quad$ ex-smoker

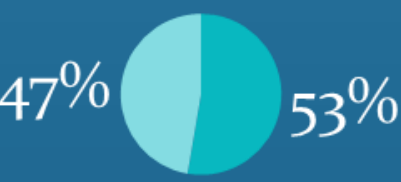

Surgery type: Iwor Lewis (59)

Transhiatal esophagectomy (4) McKeown (2)

Surgery length: $463 \pm 102 \mathrm{~min}$

Intraop fluid-therapy: $3259 \pm 1107 \mathrm{ml}$

- $73,85 \%$ extubated before CCU income

- $92,3 \%$ : negative hydric balance the first postoperative $24-48 \mathrm{~h}$

- Politransfusion: none

Conclusion

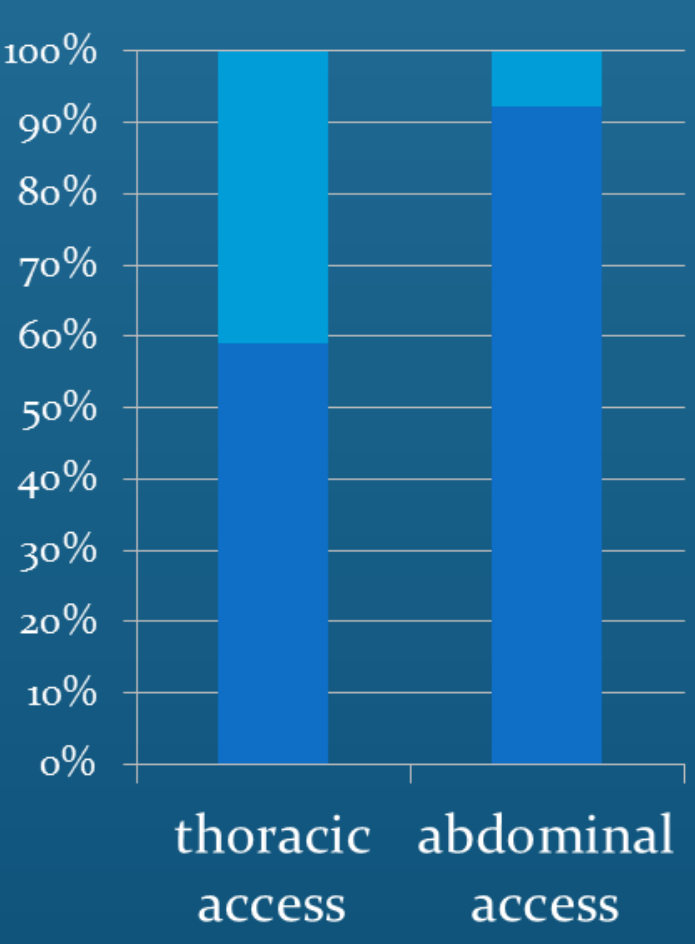

- Respiratory failure prolongs CCU stay.

- Respiratory failure is the main re-entry cause.

- Previous pulmonary disease is a risk factor for respiratory failure development.

- Extended studies are needed to allow establishing guidelines that reduce the incidence of respiratory failure and re-entry into esophageal surgery.

Bibliography:

Income stay

Mean stay 3 days $(5 \pm 7)$

RF development $13,8 \% \rightarrow$ average stay prolongation of 17,8 days $\rightarrow$ NIMV for $3 \pm 2$ days and IVM for $10 \pm 9$ days.

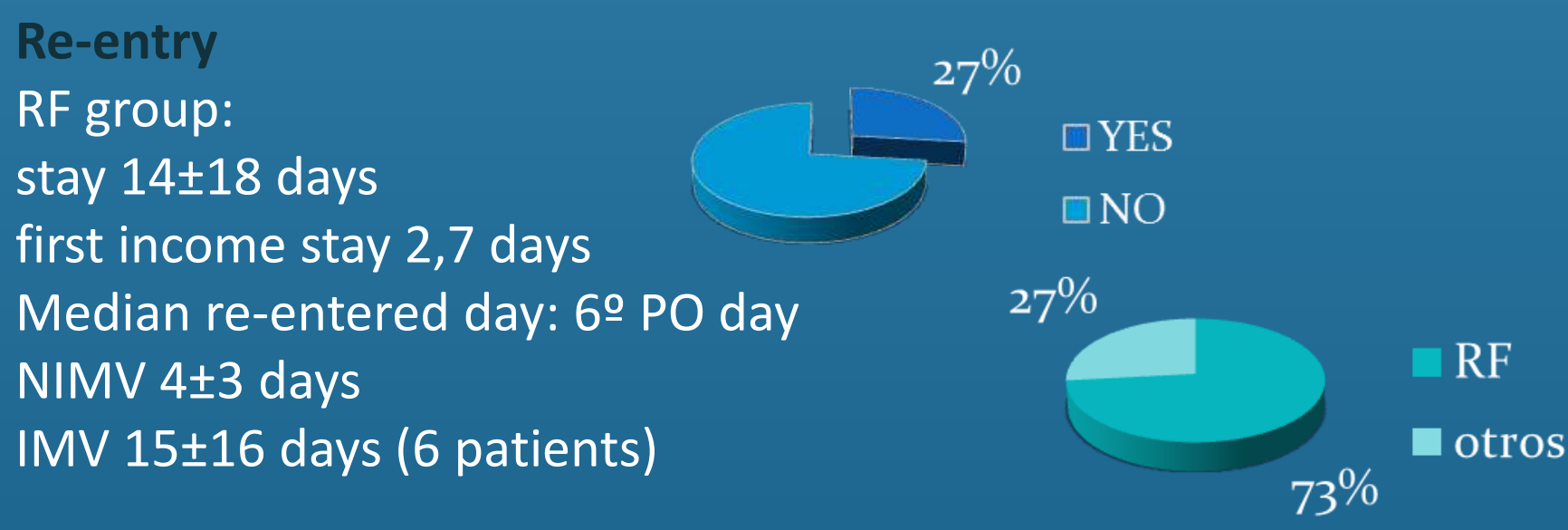

Respiratory disease is not significantly related $(p=0.06)$.

Another causes of re-entry were subfrenic abscess, pulmonary tromboembolism, suture dehiscense and coloplasty necrosis.

close

open

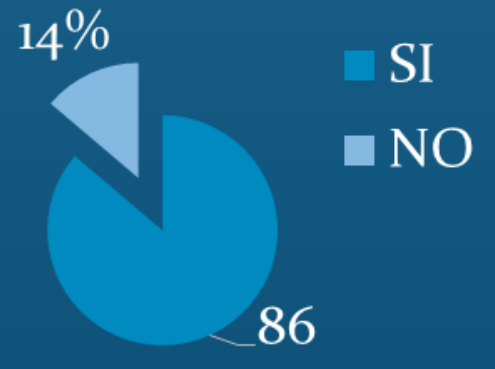

$\%$
- septic shock and multyorganfaliure (4)

- pulmonary thromboembolism (2)

- nosocomial pneumonia (1)

- acute respiratory distress syndrome (1) 